\title{
Influence of density and predators on metamorphic size in Rhinella schneideri tadpoles raised in mesocosm conditions
}

\author{
Arturo I. KeHR \& Valeria I. Gómez \\ Centro de Ecología Aplicada del Litoral (CECOAL-CONICET), Ruta 5, Km 2.5 Corrientes, Argentina C.P. 3400; e-mail: \\ arturokehr@yahoo.com.ar
}

\begin{abstract}
Amphibians exhibit extreme plasticity in the timing of metamorphosis, and several species respond to water availability, accelerating metamorphosis when their ponds dry. We analyzed the plasticity of the developmental response to water volume in Rhinella schneideri tadpoles. We raised tadpoles in mesocosm. Covariation between body size at metamorphosis and timing of development was positive. Nevertheless, the first approximately $53 \%$ of the metamorphoses finishing the cycle required between 34 and 56 days, and the covariation between body size at metamorphosis and timing of development was negative. For these tadpoles, the larval density and the presence of predators did not significantly affect their mass to metamorphosis. Nevertheless, predators affected time to metamorphosis. For the remainder of the tadpoles that reached metamorphosis at $>56$ days, the relationship between body size at metamorphosis and timing of development was positive. For these tadpoles, larval density was important for mass at metamorphosis and presence of predators was also important for time to metamorphosis. Two dominant features were observed: (i) approximately $53 \%$ of metamorphs had morphological features similar to individuals developing in desiccating ponds, and (ii) the other individuals had morphological characteristics comparable to metamorphs developing in an unchanging environment.
\end{abstract}

Key words: tadpoles; phenotypic plasticity; density; predators; trade-off; r-strategist

\section{Introduction}

The influence of biotic and abiotic factors on tadpole life cycles differs depending on whether the environment is predictable or unpredictable. A temporary pond habitat has two important characteristics for tadpoles: first, explosive primary productivity stimulates rapid growth (Wassersug 1975); second, fish and other large predators (insects) are typically absent (Wilbur 1980).

Many studies have dealt with the effect of density on the intensity of competition at the specific or community level, and on predation (Kehr 1989; Relyea 2004; Bolnick \& Preisser 2005; Teplitsky \& Laurila 2007). High density (crowding) has been shown to negatively affect survivorship, growth rate, and the length of larval period of amphibian larvae (Kehr 1994; Relyea 2002).

Nevertheless, biotic factors can be minimized by the influence of abiotic effects (Warner et al. 1991). Pond desiccation is one of the most important abiotic factors regulating larval amphibian populations (Kehr 1997; Maciel \& Juncá 2009; Richter-Boix et al. 2011). Natural selection may lead to several strategies to deal with habitat unpredictability. Strong selection for fast development would reduce the risk of death by desiccation and reduce phenotype variation in the environment. Natural selection can alter the phenotypic range of populations in the current generation by serving as a filter that favors the survival of particular phenotypes (Kingsolver 1995; Van Buskirk \& Relyea 1998).

Tadpoles can respond to predators in different ways. They may minimize the risk of predation by changing their habitat (Werner \& Peacor 2003), their life history (Benard 2004; Fusco \& Minelli 2010), behavior and growth (Relyea \& Werner 1999; Babbit 2001; Peacor 2002; Relyea 2007), or by developing chemical or morphological defenses. Predator-induced changes in body morphology have, however, been described in tadpoles (Relyea 2003, 2004; Jara \& Perotti 2009; Gómez \& Kehr 2011a, b, 2012). Another possibility is that the phenotype may be modified by developmental responses to environmental variations. Concurrently, environmental conditions can have substantial impacts on phenotypes by inducing changes in behavior, morphology, physiology, or life history of most organisms, and these changes are often in adaptive directions (WestEberhard 1989; Tollrian \& Harvell 1999). Although tadpoles may display phenotypic plasticity, several mechanisms may reduce variability in metamorphic size producing a dilution of this trade-off (Tejedo \& Reques 1994).

Covariation between the length of the larval period and size at metamorphosis may be influenced both by environmental factors (Travis 1984; Griffiths 1991; Pfennig et al. 1991). A positive correlation between size at metamorphosis and length of the larval period sug- 
gests a trade-off between growing large and metamorphosing quickly to avoid pond desiccation or predation. Nevertheless, negative correlations between size at metamorphosis and length of the larval cycle, implying no trade-off have been described occasionally in experimental and natural ponds (Pfenning et al. 1991; Tejedo \& Reques 1992, 1994).

This study was carried out with Rhinella schneideri (Werner, 1894) tadpoles. This common species in northeastern Argentina can reproduce continuously from August until March, depending on rainfall. This species breeds in either temporary or semipermanent ponds. The main goals of this work were: (i) to describe the effects of density; (ii) to observe the effect of predator presence, and (iii) to analyze covariation between time at metamorphosis and metamorph size in each treatment. Results were obtained by analyzing: a) mass at metamorphosis, b) survival, c) time to metamorphosis, and d) growth rate under various conditions.

\section{Material and methods}

\section{Experimental design}

The experiment was performed in 12 artificial ponds located in the field of the Centro de Ecología Aplicada del Litoral (CECOAL-CONICET) $12 \mathrm{~km}$ from Corrientes City, Argentina $\left(27^{\circ} 30^{\prime} \mathrm{S}, 58^{\circ} 45^{\prime} \mathrm{W}\right)$. The artificial ponds $(0.90$ $\mathrm{m}$ in diameter and $0.80 \mathrm{~m}$ deep) were filled with $400 \mathrm{~L}$ of water one month before beginning the experiment. To each tank we added $0.5 \mathrm{~L}$ every $10 \mathrm{~d}$ of a standard inoculum of plankton and periphyton filtered from two natural ponds. In addition, every 10 days we added $2 \mathrm{~g}$ (dry weight) of lettuce previously boiled for $10 \mathrm{~min}$ and $3 \mathrm{~g}$ of fish food (commercial brand Shulet). During the experience the dissolved oxygen ranged between $3.3-3.8 \mathrm{mg} \mathrm{L}^{-1}$, $\mathrm{pH}$ between 6.6-6.8, and the air mean temperature $\left({ }^{\circ} \mathrm{C}\right)$ ranged between 22-26 (minimum $18^{\circ} \mathrm{C}$ and maximum $32^{\circ} \mathrm{C}$ ).

We used a randomized block design with a factorial combination of two densities of tadpoles (150 and 300) and two predator presence (presence - absence). The four treatments were arranged in three randomly replicated spatial blocks with a total of 12 tanks. The predators used were Belostoma micantulum Stal, 1858 (Hemiptera: Belostomatidae). We used three individuals of $B$. micantulum in each tank.

The $R$. schneideri eggs were obtained from three different clutches within a large ephemeral pond located near Corrientes city. The tadpoles were mixed and added to the tanks when they were five days old (Stages 25-26, Gosner 1960). The experiment began on $18^{\text {th }}$ September 1999 .

We measured the effect of larval density and the presence of insect predators on larval survival, mass at metamorphosis, time to metamorphosis, and growth rate on R. schneideri.

\section{Statistical analyses}

The statistical test used was a Multivariate Analysis of Variance of two factors (MANOVA). This test allowed us to separate the effect of predators and density (both independent factors) on the following dependent variables: (1) mass at metamorphosis measured at tail absorption (stage 46; Gosner 1960) to the nearest $0.1 \mathrm{mg}$; (2) time to metamorphosis, or the interval from the start of the experiment until tail absorption (Gosner stage 46), and (3) survival to metamorphosis, measured as the percent of metamorphosis in each tank. In those cases where significant MANOVA results were observed, this analysis was supplemented with a univariate variance analysis (ANOVA) to detect which factor exercised the most influence.

After the first metamorphs (Gosner 42-43) were discovered, tanks were checked daily and all metamorphs found were collected and maintained in the laboratory in plastic containers (15 cm diameter) arranged in an inclined plane of 15 degree and $2 \mathrm{~cm}$ of water until tail absorption was completed (Gosner stage 46).

Mass and time to metamorphosis were $\log _{e}$ transformed due to heterogeneity of variances among treatments. Survival data were angularly transformed by the arcsine square root transformation. With these transformations, the distribution of the data approached normality. A previous analysis showed that the main effect of blocks did not exhibit a significant effect on the response variables. Therefore, blocks were pooled across treatments. All statistical analyses were performed using the software SYSTAT 7.0 for Windows. All values are expressed as mean $\pm 1 \mathrm{SD}$.

The growth rates of tadpoles $\left(\mathrm{mg} \mathrm{day}^{-1}\right)$ under different experimental conditions were compared using the "General Linear Model" (GLM) which allowed us to compare the homogeneity ("parallelism") in the slope (b) of the regression between mass and time to metamorphosis. This was calculated by an ANCOVA using the variable "time" as the covariable of the pattern. This method permits comparison of the different values of the constant b (regression coefficient) of the regression equation.

In order to analyze the relationship between size at metamorphosis and time to metamorphosis, at different moments of development time, that span of time was divided into three periods of approximately 22 days (first period: between 34 and 56 days; second period: between 57 and 78 days, and third period: between 79 and 102 days). We considered these 68 first days (time between 34 and 102 days) as adequate for analyzing the relationship between the dependent variables (mass at metamorphosis and development time) and the two factors for each of the three periods predator presence and density (150 vs. 300 tadpoles). Survival for each period was not considered because we took the data from throughout the time of development and not for a particular time.

\section{Results}

A MANOVA test suggested that the combined responses of mass and time to metamorphosis, and survival to metamorphosis were significantly affected by presence of predators and larval density (Wilks' Lambda $<0.001)$ (Table 1 ). The MANOVA test also revealed that the interaction between predator presence and larval density affected significantly the three dependent variables. The following univariate results showed the variables responsible for these complete treatment effects.

\section{Predators effects}

Mass to metamorphosis differed significantly between treatments (Table 1 ). The mean mass of tadpoles in tanks without predators $(\bar{x}=120.48 \pm 30.66 \mathrm{mg}, n=$ 293) was lower than tadpoles that developed in tanks 
Table 1. Results of the analysis of MANOVA and ANOVA carried out with Rhinella schneideri tadpoles. Probabilities for the univariate test (ANOVA) were compared with the level of adjusted significance for the three dependent variables according to that proposed by Bonferroni ( $\alpha=0.016)$.

\begin{tabular}{|c|c|c|c|}
\hline $\begin{array}{l}\text { Variable PREDATOR } \\
\text { MANOVA (Wilk's Lambda }=0.700 ; \mathrm{df}=3,342 ; P<0.001)\end{array}$ & $\mathrm{df}$ & $F$ & $P$ \\
\hline $\begin{array}{l}\text { Univariate } \mathrm{F} \text { test } \\
\text { Mass at metamorphosis } \\
\text { Time to metamorphosis } \\
\text { Survival to metamorphosis }\end{array}$ & $\begin{array}{l}1,344 \\
1,344 \\
1,344\end{array}$ & $\begin{array}{r}10.499 \\
21.741 \\
136.411\end{array}$ & $\begin{array}{r}0.001 \\
<0.001 \\
<0.001\end{array}$ \\
\hline $\begin{array}{l}\text { Variable DENSITY } \\
\text { MANOVA (Wilk's Lambda }=0.656 ; \mathrm{df}=3,342 ; P<0.001 \text { ) }\end{array}$ & & & \\
\hline $\begin{array}{l}\text { Univariate } \mathrm{F} \text { test } \\
\text { Mass at metamorphosis } \\
\text { Time to metamorphosis } \\
\text { Survival to metamorphosis }\end{array}$ & $\begin{array}{l}1,344 \\
1,344 \\
1,344\end{array}$ & $\begin{array}{r}0.035 \\
27.039 \\
167.754\end{array}$ & $\begin{array}{r}0.852 \\
<0.001 \\
<0.001\end{array}$ \\
\hline $\begin{array}{l}\text { Variable PREDATOR } \times \text { DENSITY } \\
\text { MANOVA (Wilk's Lambda }=0.742 ; \mathrm{df}=3,342 ; P<0.001)\end{array}$ & & & \\
\hline $\begin{array}{l}\text { Univariate } \mathrm{F} \text { test } \\
\text { Mass at metamorphosis } \\
\text { Time to metamorphosis } \\
\text { Survival to metamorphosis }\end{array}$ & $\begin{array}{l}1,344 \\
1,344 \\
1,344\end{array}$ & $\begin{array}{r}8.448 \\
13.186 \\
93.729\end{array}$ & $\begin{array}{r}0.004 \\
<0.001 \\
<0.001\end{array}$ \\
\hline
\end{tabular}

with predators $(\bar{x}=134.00 \pm 39.88 \mathrm{mg}, n=55)$. Furthermore, in tanks with predators the standard deviation was greater, reflecting major variability in the mass to metamorphosis of these tadpoles.

Time to metamorphosis was significantly different between treatments (Table 1). The mean time of tadpoles in the tanks without predators was shorter $(\bar{x}=$ $58.47 \pm 23.47$ days, $n=293)$ than the mean time to metamorphosis of tadpoles in tanks with predators $(\bar{x}=81.30 \pm 19.04$ days, $n=55)$.

Survival to metamorphosis was significantly different between treatments (Table 1). Survival proportion of tadpoles in the tanks without predators was greater $(\bar{x}=0.598 \pm 0.29, n=293)$ than tanks with predators $(\bar{x}=0.06 \pm 0.03, n=55)$.

\section{Larval density effects}

Mass at metamorphosis was not significantly different between treatments (Table 1 ). The mean mass of tadpoles in tanks with low density (0.375 larvae per liter) $(\bar{x}=121.99 \pm 29.45 \mathrm{mg}, n=277)$ was slightly lower than tadpoles that developed in tanks with high density (0.75 larvae per liter) $(\bar{x}=125.07 \pm 42.92 \mathrm{mg}$, $n=71)$.

Time to metamorphosis was significantly different between treatments (Table 1). The mean time of tadpoles in tanks with low density was less $(\bar{x}=$ $55.88 \pm 16.50$ days, $n=277)$ than the mean time of tadpoles in tanks with high density $(\bar{x}=86.25 \pm 33.24$ days, $n=71$ ).

Survival to metamorphosis was significantly different between treatments (Table 1). The proportion of tadpoles that survived in tanks with low density was greater $(\bar{x}=0.631 \pm 0.264, n=277)$ than the proportion of tadpoles in tanks with high density $(\bar{x}=$ $0.058 \pm 0.018, n=71$ ).
General relationship between the mass to metamorphosis and development time

Size at metamorphosis for all metamorphs $(n=348)$, was positively correlated with development time in tadpoles raised under the two factors, predators and density.

Significant differences were observed (GLM ANOVA, $\left.F_{1,344}=5.32, P=0.021\right)$ in the growth rates of tadpoles in the presence of predators $(b=$ $0.97)$ versus without predators $(b=0.45)$. Growth rates of tadpoles developing in different larval densities $(b=0.68$ and $b=0.64 ; 150$ and 300 tadpoles respectively) showed no significant differences (GLM ANOVA, $\left.F_{1,344}=0.087, P=0.76\right)$.

Relationship between mass and time to metamorphosis (34 and 56 days of development)

Predators effect

The mass of metamorphs that reached the metamorphosis between 34 and 56 days of development was not significantly different between tadpoles reared in tanks with presence and absence of predators (Table 2). The mean mass of tadpoles in tanks without predators $(\bar{x}=110.38 \pm 21.79 \mathrm{mg}, n=181)$ was higher than of those developed in tanks with predators $(\bar{x}=$ $102.00 \pm 21.68 \mathrm{mg}, n=5$ ).

Time to metamorphosis was significantly different between treatments (Table 2). The mean time of tadpoles in tanks without predators was lower $(\bar{x}=$ $45.19 \pm 5.37$ days, $n=181)$ than the mean time of tadpoles in tanks with predators $(\bar{x}=50.80 \pm 3.76$ days, $n=5)$.

\section{Density effects}

Mass of metamorphs that reached metamorphosis between 34 and 56 days of development was not signifi- 
Table 2. Summary of analysis of mass to metamorphosis and time to metamorphosis of Rhinella schneideri tadpoles with the factors predators (presence - absence) and densities (150 vs. 300 tadpoles) using ANOVA tests (dependent variables were previously transformed to natural logarithms). The three time periods correspond to time tadpoles spent until metamorphosis. For these analyses the first metamorphs needed 34 days and the latter 102 days. During this time 316 tadpoles reached to metamorphosis.

\begin{tabular}{|c|c|c|c|c|c|c|c|c|c|}
\hline & \multicolumn{3}{|c|}{ Between 34 and 56 days $(n=186)$} & \multicolumn{3}{|c|}{ Between 57 and 78 days $(n=93)$} & \multicolumn{3}{|c|}{ Between 79 and 102 days $(n=37)$} \\
\hline & Predators & Density & $\begin{array}{l}\text { Predators } \\
\times \text { density }\end{array}$ & Predators & Density & $\begin{array}{l}\text { Predators } \\
\times \text { density }\end{array}$ & Predators & Density & $\begin{array}{l}\text { Predators } \\
\times \text { density }\end{array}$ \\
\hline $\begin{array}{l}\text { Mass to } \\
\text { meta- } \\
\text { morphosis }\end{array}$ & $\begin{array}{c}F_{(1,182)}= \\
<0.001 ; \\
P=0.99\end{array}$ & $\begin{array}{c}F_{(1,182)}= \\
0.015 ; \\
P=0.90\end{array}$ & $\begin{array}{c}F_{(1,182)}= \\
8.36 ; \\
P<0.01^{*}\end{array}$ & $\begin{array}{c}F_{(1,89)}= \\
1.97 \\
P=0.16\end{array}$ & $\begin{array}{c}F_{(1,89)}= \\
11.47 ; \\
P<0.01 *\end{array}$ & $\begin{array}{c}F_{(1,89)}= \\
5.37 \\
P=0.02^{*}\end{array}$ & $\begin{array}{c}F_{(1,33)}= \\
0.32 ; \\
P=0.57\end{array}$ & $\begin{array}{c}F_{(1,33)}= \\
0.101 ; \\
P=0.75\end{array}$ & $\begin{array}{c}F_{(1,33)}= \\
5.397 ; \\
P=0.02 *\end{array}$ \\
\hline $\begin{array}{l}\text { Time to } \\
\text { meta- } \\
\text { morphosis }\end{array}$ & $\begin{array}{c}F_{(1,182)}= \\
4.62 ; \\
P=0.03^{*}\end{array}$ & $\begin{array}{c}F_{(1,182)}= \\
0.906 ; \\
P=0.34\end{array}$ & $\begin{array}{c}F_{(1,182)}= \\
1.82 ; \\
P=0.18\end{array}$ & $\begin{array}{c}F_{(1,89)}= \\
9.19 ; \\
P<0.01^{*}\end{array}$ & $\begin{array}{c}F_{(1,89)}= \\
0.22 ; \\
P=0.63\end{array}$ & $\begin{array}{c}F_{(1,89)}= \\
1.07 ; \\
P=0.30\end{array}$ & $\begin{array}{c}F_{(1,33)}= \\
1.408 \\
P=0.24\end{array}$ & $\begin{array}{c}F_{(1,33)}= \\
0.047 ; \\
P=0.83\end{array}$ & $\begin{array}{c}F_{(1,33)}= \\
0.017 \\
P=0.89\end{array}$ \\
\hline
\end{tabular}

Table 3. Summary of Rhinella schneideri metamorphs between 34 and 102 days (first and last days) for each treatment. The regression equation corresponds to the relationship between weight on metamorphic climax and time of development. In those cases where adjustment of the data to regression was not significant, the Spearman Rank Correlations test was used. In the column corresponding to mass and time, the data correspond to the arithmetic mean and 1 standard deviation (in parenthesis). * significant.

\begin{tabular}{|c|c|c|c|c|}
\hline & Treatment & Regression & Mass (mg) & Time (days) \\
\hline $\begin{array}{l}\text { Between } 34 \\
\text { and } 56 \text { days }\end{array}$ & $\begin{array}{l}\text { Predators } \\
\text { No predators } \\
\text { Density } 150 \\
\text { Density } 300\end{array}$ & $\begin{array}{l}\text { Spearman Rank; } R s=0.81, n=5, P>0.05 \\
y=137.7-0.604 x ; r=0.15 ; F_{(1,179)}=4.07, n=181, P=0.04^{*} \\
y=141.20-0.639 x ; r=0.17 ; F_{(1,164)}=5.02, n=166, P=0.02^{*} \\
\text { Spearman Rank; Rs }=-0.096, n=20, P>0.05\end{array}$ & $\begin{array}{r}102.00(21.67) \\
110.38(21.79) \\
112.23(20.22) \\
93.00(26.77)\end{array}$ & $\begin{array}{l}50.80(3.76) \\
45.19(5.37) \\
45.32(5.45) \\
45.55(5.13)\end{array}$ \\
\hline $\begin{array}{l}\text { Between } 57 \\
\text { and } 78 \text { days }\end{array}$ & $\begin{array}{l}\text { Predators } \\
\text { No predators } \\
\text { Density } 150 \\
\text { Density } 300\end{array}$ & $\begin{array}{l}\text { Spearman Rank; } R s=0.48, n=22, P<0.05^{*} \\
y=-23.50+2.45 x ; r=0.35 ; F_{(1,69)}=9.58, n=71, P=0.003^{*} \\
y=38.59+1.45 x ; r=0.24 ; F_{(1,82)}=5.12, n=84, P=0.026^{*} \\
\text { Spearman Rank; } R s=0.64, n=9, P<0.05^{*}\end{array}$ & $\begin{array}{l}119.54(29.19) \\
132.71(33.04) \\
132.29(31.34) \\
104.44(34.31)\end{array}$ & $\begin{array}{l}68.54(6.19) \\
63.64(4.70) \\
64.54(5.23) \\
67.44(7.19)\end{array}$ \\
\hline $\begin{array}{l}\text { Between } 79 \\
\text { and } 102 \text { days }\end{array}$ & $\begin{array}{l}\text { Predators } \\
\text { No predators } \\
\text { Density } 300\end{array}$ & $\begin{array}{l}\text { Spearman Rank; } R s=0.11, n=28, P>0.05 \\
\text { Spearman Rank; } R s=-0.067, n=41, P>0.05 \\
y=-196.28+3.93 x ; r=0.54 ; F_{(1,16)}=6.62, n=18, P=0.02^{*}\end{array}$ & $\begin{array}{l}151.07(42.28) \\
143.90(39.10) \\
144.76(39.89)\end{array}$ & $\begin{array}{r}96.78(11.82) \\
108.14(21.92) \\
109.66(20.42)\end{array}$ \\
\hline
\end{tabular}

cantly different between the tadpoles reared at the two densities (Table 2). The mean mass of tadpoles in tanks with low density $(\bar{x}=112.23 \pm 20.22 \mathrm{mg}, n=166)$ was higher than of tadpoles that developed in tanks with predators $(\bar{x}=93.00 \pm 26.77 \mathrm{mg}, n=20)$.

Differences in time to metamorphosis were not significant between larval densities (Table 2). The mean time of tadpoles in tanks with low density $(\bar{x}=$ $45.32 \pm 5.45$ days, $n=166)$ was similar to the mean time of tadpoles in tanks with high density $(\bar{x}=$ $45.55 \pm 5.13$ days, $n=20)$.

The interaction between predators $\times$ density was significant for mass to metamorphosis but not for time of development.

During this period, the relation between size to metamorphosis and time of development, was linear, negative and significant for tadpoles reared in tanks without predators and in tanks with lower density (Fig. 1A; Table 3). Metamorphs that developed in tanks with higher density displayed a negative but not significant relationship. The few metamorphs that developed in tanks with predators $(n=5)$ showed a positive but not significant relationship between both variables.
Relationship between mass and time to metamorphosis (57 and 78 days of development)

\section{Predators effect}

Mass of metamorphs that reached metamorphosis between 57 and 78 days of development was not significantly different between tadpoles reared in the two conditions (Table 2). The mean mass of tadpoles in tanks without predators $(\bar{x}=132.72 \pm 33.04 \mathrm{mg}, n=71)$ was higher than of tadpoles that developed in tanks with predators $(\bar{x}=119.54 \pm 29.19 \mathrm{mg}, n=22)$.

Differences in time to metamorphosis were significant between the two conditions (Table 2). The mean time of tadpoles in tanks without predators $(\bar{x}=63.65 \pm 4.70$ days, $n=71)$ was lower than the mean time of tadpoles in tanks with predators $(\bar{x}=$ $68.54 \pm 6.19$ days, $n=22$ ).

\section{Density effect}

Mass of metamorphs that reached metamorphosis between 57 and 78 days of development was significantly different between tadpoles reared in the two densities (Table 2). The mean mass of tadpoles in tanks with low density $(\bar{x}=132.30 \pm 31.34 \mathrm{mg}, n=84)$ was higher than of those tadpoles that developed in tanks with 

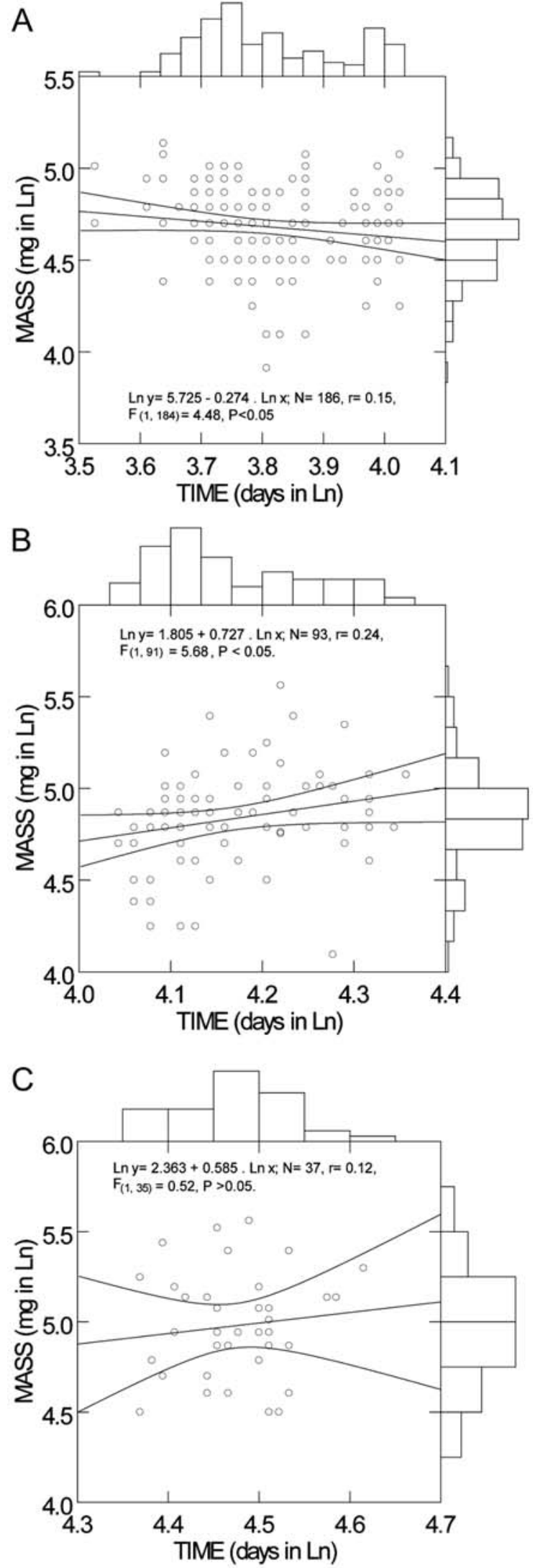

Fig. 1. Linear regression between mass to metamorphosis and time to metamorphosis during three periods of development of Rhinella schneideri tadpoles. A: metamorphosed during 34 to 56 days; B: metamorphosed during 57 to 78 days, and C: metamorphosed during 79 to 102 days. The histogram represents frequency of individuals in relation to mass and time to metamorphosis. In total, 316 individuals metamorphosed during 34 to 102 days. high density $(\bar{x}=104.44 \pm 34.32 \mathrm{mg}, n=9)$.

Differences in time to metamorphosis were not significant between the densities (Table 2). The mean time to metamorphosis for tadpoles in tanks with low density $(\bar{x}=64.52 \pm 5.23$ days, $n=84)$ was slightly lower than the mean time of tadpoles in tanks with high density $(\bar{x}=67.44 \pm 7.19$ days, $n=9)$.

The interactions between predators $\times$ density was significant for mass at metamorphosis but not significant for time of development.

During this period, the relationship between mass at metamorphosis and time of development was linear, positive and significant for all treatments (Fig. 1B; Table 3$)$.

Relationship between mass and time to metamorphosis (79 and 102 days of development)

\section{Predators effects}

Mass of metamorphs that reached metamorphosis between 79 and 102 days of development was not significantly different between tadpoles reared in the two conditions (Table 2). The mean mass of tadpoles in tanks without predators $(\bar{x}=148.95 \pm 48.75 \mathrm{mg}, n=19)$ was slightly lower than of tadpoles that developed in tanks with predators $(\bar{x}=153.90 \pm 42.03 \mathrm{mg}, n=18)$.

Differences in time to metamorphosis were not significantly different between both conditions (Table 2). The mean time of tadpoles in tanks without predators $(\bar{x}=86.32 \pm 4.24$ days, $n=19)$ was slightly lower than the mean time of tadpoles in tanks with predators $(\bar{x}=$ $89.27 \pm 5.99$ days, $n=18$ ).

\section{Density effect}

Mass of metamorphs that reached metamorphosis between 79 and 102 days of development was not significantly different between tadpoles reared at the two densities (Table 2). The mean mass of tadpoles in tanks with low density $(\bar{x}=150.52 \pm 47.54 \mathrm{mg}, n=19)$ was similar to tadpoles that developed in tanks with high density $(\bar{x}=152.22 \pm 43.59 \mathrm{mg}, n=18)$.

Differences in time to metamorphosis were not significantly different between densities (Table 2). The mean time of tadpoles in tanks with low density $(\bar{x}=$ $86.74 \pm 4.49$ days, $n=19$ ) was lower than the mean time of tadpoles in tanks with high density $(\bar{x}=$ $88.83 \pm 6.00$ days, $n=18$ ).

The interactions between predators $\times$ density was significant for mass to metamorphosis but not significant for time of development (Table 2).

During this period, there was no linear and significant relation between mass at metamorphosis and time of development (Fig. 1C; Table 3).

\section{Discussion}

\section{General ecological implication}

In general, the mass at metamorphosis of Rhinella schneideri tadpoles was dependent only on predator presence and independent of initial density. The time to metamorphosis and survival were dependent on two 
factors: predators and density. The controversial results obtained concerning the lack of density dependence of mass to metamorphosis can be explained by the habitat stability, which influences the time to metamorphosis. More time in a stable habitat (e.g., water level without fluctuations), the mass of tadpoles reaches the maximum at the metamorphic climax. Simultaneously, the density changed as the tadpoles metamorphosed. This situation produced a general positive covariation between mass at metamorphosis and time to metamorphosis.

The responses on performance from a general standpoint are similar to other species in field experiments, where the magnitude of the effect caused by the density of tadpoles on metamorphic size was not large (Loman 2004). Density regulation produces a clear effect on tadpole performance in laboratory studies. In field conditions, the results are less clear. While Berven (1990) and Skelly (1995) have found evidence of density regulation in anuran larvae, other studies, (Loman 2004) have provided little evidence for such regulation. In other words, the real dimension of density regulation in anuran larvae can change according to different development time.

Ecological implications in particular time of reaching metamorphosis. 34 to 56 days of time to metamorphosis This first period (between 34 and 56 days to reach metamorphosis) had the largest number of metamorphs reaching the climax $(n=186 ; 53 \%)$. The predators and density factors were not significant for mass at metamorphosis. Presence of predators in the tanks significantly affected time to metamorphosis and number of metamorphs reaching metamorphosis. For the individuals of $R$. schneideri reaching metamorphosis between 34 and 56 days of development (53\% of all juveniles), under stable conditions, the density was less important than the stress produced by predator presence. Predators can have significant lethal and non-lethal effects on prey through chemically mediated interactions. Some amphibian larvae often respond to predators by altering behavior (i.e., decreasing mobility) or morphology (developing longer tails, deeper tail fins and pronounced tail musculature that increases swimming ability) (Petranka \& Hayes 1998; Anderson \& Petranka 2003; Gómez 2012).

During this period the covariation between mass at metamorphosis and time to metamorphosis was negative, implying no trade-off. This feature has been reported only rarely in experimental and natural ponds and is generally associated with seasonally decreasing food resources (Pfenning et al. 1991). Kehr \& Marangoni (1999) reported a negative relationship between mass at metamorphosis and time to metamorphosis for tadpoles of $R$. schneideri in natural conditions by the gradual drying of the pond. Newman (1988) and Pfennig et al. (1991) also observed negative correlations between the size and the time of metamorphosis in tadpoles of the genus Scaphiopus in habitats whose duration was modified in an experimental array. Reques
\& Tejedo (1995) also reported a negative relationship between these variables in larvae of Bufo calamita (Laurenti, 1768) in natural conditions, also due to increasing water temperature.

In our experiment, the water level was constant, without much fluctuation in water temperature throughout the larval development. We suggest that the absence of trade-off in the $R$. schneideri tadpoles in the first third of the time to reach metamorphosis was not influenced by abiotic or biotic interactions. In contrast, the stability of the environment lead to the observed trade-off changes in relation to the prolonged time to metamorphosis for the tadpoles that remained in the tanks. Absence of a trade-off for $53 \%$ of tadpoles arriving to metamorphic climax may be related to the life strategy. Rhinella schneideri is a typical r-selected species characterized by reproduction usually in unpredictable and temporary habitat immediately after rainfall. The adaptation of this species for rapid development and early metamorphosis for most tadpoles may be caused by genetic factors favoring tadpoles that grow fast with better characteristics, such as more mobility, greater growth rate and development rate.

Ecological implication for tadpoles arriving to metamorphosis between 57-78 days

In these individuals the mass to metamorphosis was significantly affected by the density and the interactions between predators and density, and not by the predators alone. The presence of predators directly influenced time to metamorphosis. Under stable conditions and when the time to metamorphosis is longer, density was important for mass to metamorphosis and the predators, similar to the first period, was also important for time to metamorphosis.

The covariation between mass and time at metamorphosis was a positive relationship. The mean mass to metamorphosis was greater than the mass obtained in the tadpoles that reached metamorphosis between 34-56 days. During this time, 93 (27\% of the total) individuals reached metamorphic climax.

Ecological implication for tadpoles arriving to metamorphosis between 79-102 days

Between 79 and 102 days of development only the interactions between predators $\mathrm{x}$ density was significant on mass to metamorphosis. In this third period the two factors were not important on the metamorphs that finished their larval cycles.

Similar to the second period, a positive relationship in the covariation of mass at metamorphosis and development time was observed in the metamorphs of this period. Furthermore, the mean mass of metamorphs was greater than the mean mass of metamorphs from the two prior periods.

For the tadpoles that reached metamorphosis between 57-102 days of development, the presence of a trade-off between mass at metamorphosis and time to metamorphosis implies the reversibility of this feature. When there is a substantial cost of possessing a par- 
ticular phenotype in the "wrong" environment, selection should favor the evolution of reversibility (Gabriel 1999). Variable environments should favor phenotypic reversibility in a species. Even if the water level were constant throughout the larval cycle, biotic factors would still change with development time (density, intraspecific competition, predator-prey relation, etc.).

In summary, for the $R$. schneideri tadpoles that usually breed in ephemeral ponds, the influences of biotic factors changed in response to habitat stability. As a typical newly born r-strategist, the main objective is to grow rapidly and reach a minimum size threshold to begin metamorphosis. For these individuals that have a negative covariation between mass at metamorphosis and time to metamorphosis, the priority is to reach the metamorphic climax, independent of habitat conditions. Furthermore, the coefficient of variation of the mass metamorphosis in these juveniles is lower than that recorded for individuals that metamorphosed between 57-78 and 79-102 days.

\section{Acknowledgements}

We are very indebted to M. Crump and R. Wassersug for reading an earlier version of the manuscript and providing helpful comments; and Consejo Nacional de Investigaciones Científicas y Técnicas (CONICET) from Argentina, through grant PIA 6393 for funding this research. Furthermore, we are especially indebted to M. I. Duré and M. I. Hamann for helping in the laboratory and fieldwork.

\section{References}

Anderson A.R. \& Petranka J.W. 2003. Odonate predator does not affect hatching time or morphology of embryos of two amphibians. J. Herpetol. 37 (1): 65-71. DOI: 10.1670/00221511(2003)037[0065:OPDNAH]2.0.CO;2

Babbit K.J. 2001. Beaviour and growth of southern leopard frog (Rana sphenocephala) tadpoles: effects of food and predation risk. Can. J. Zool. 79 (5): 809-814. DOI: 10.1139/z01-040

Benard M.F. 2004. Predator-induced phenotypic plasticity in organism with complex life cycles. Annu. Rev. Ecol. Evol. Syst. 35 (2004): 651-673. DOI: 10.1146/annurev.ecolsys.35.021 004.112426

Berven K.A. 1990. Factors affecting populations fluctuations in larval and adult stages of the wood frog (Rana sylvatica). Ecology 71: 1599-1608. DOI: http://dx.doi.org/10.2307/ 1938295

Bolnick D.I. \& Preisser E.L. 2005. Resource competition modifies the strength of trait-mediated predator-prey interactions: a meta-analysis. Ecology 86: 2771-2779. DOI: http://dx.doi.org/10.1890/04-1249

Fusco G. \& Minelli A. 2010. Phenotipic plasticity in developmental and evolution: facts and concepts. Philos. Trans. R. Soc. Lond. B Biol. Sci. 365 (1540): 547-556. DOI: 10.1098/rstb.2009.0267

Gabriel W. 1999. Evolution of reversible plastic responses: inducible defenses and environmental tolerance, pp. 286-305. In: Tollrian R. \& Harvell D. (eds), The Ecology and Evolution of Inducible Defenses, Princeton University Press, Princeton, New Jersey, 395 pp. ISBN: 9780691004945

Gómez V.I. 2012. Respuestas fenotípicas en larvas de anuros a situaciones cambiantes en los factores bióticos y abióticos. Tesis Doctoral, Universidad Nacional de La Plata, Facultad de Ciencias Naturales Museo, 194 pp.
Gómez V.I. \& Kehr A.I. 2011a. Morphological and developmental responses of anuran larvae (Physalaemus albonotatus) to chemical cues from the predators Moenkhausia dichoroura (Characiformes: Characidae) and Belostoma elongatum (Hemiptera: Belostomatidae). Zool. Stud. 50 (2): 203210.

Gómez V.I. \& Kehr A.I. 2011b. Morphological and developmental plasticity in larvae of Physalaemus santafecinus (Anura: Leiuperidae) in response to chemical cues of different predators. Phyllomedusa: J. Herpetol. 10 (2): 143-151. DOI: http://dx.doi.org/10.11606/issn.2316-9079.v10i2p143-151

Gómez V.I. \& Kehr A.I. 2012. Effects of predator fish and water bugs on morphology and development of tadpoles of Elachistocleis bicolor (Anura: Microhylidae). Biologia 67 (5): 10011006. DOI: $10.2478 / \mathrm{s} 11756-012-0082-1$

Gosner K.L. 1960. A simplified table for staging anuran embryos and larvae with notes on identification. Herpetologica 16 (3): $183-190$.

Griffiths R. A. 1991. Competition between common frog, Rana temporaria, and natterjack toad, Bufo calamita, tadpoles: the effect of competitor density and interaction level on tadpole development. Oikos 61 (2): 187-196.

Jara F.G. \& Perotti M.G. 2009. Tadpoles responses to predation risk. Ontogenetic change between constitutive and inducible defenses. J. Herpetol. 43 (1): 82-88. DOI: http://dx.doi.org/ 10.1670/07-229R2.1

Kehr A.I. 1989. Factores dependientes de la densidad y su influencia sobre el crecimiento individual de los estados larvales de Hyla pulchella pulchella (Amphibia:Anura). Limnobios 2: 757-761.

Kehr A.I. 1994. Patrones de dispersión espacio-temporales y su influencia en la biología larval de Bufo arenarum (Amphibia: Anura). Neotrópica 40: 35-40.

Kehr A.I. 1997. Stage-frequency and habitat selection of a cohort of Pseudacris ocularis tadpoles (Hylidae: Anura) in a Florida temporary pond. Herpetol. J. 7 (3): 103-109.

Kehr A.I. \& Marangoni F. 1999. Variación intrapoblacional en el crecimiento y tamańo en la metamorfosis de Bufo paracnemis, bajo condiciones naturales. Neotrópica 45: 63-68.

Kingsolver J.G. 1995. Fitness consequences of seasonal polyphenism in western white butterflies. Evolution 49 (5): 942954

Loman J. 2004. Density regulation in tadpoles of Rana temporaria: a full pond field experiment. Ecology 85 (6): 16111618.

Maciel T.A. \& Juncá F.A. 2009. Effects of temperature and volume of water on the growth and development of tadpoles of Pleurderma diplolister and Rhinella granulosa (Amphibia: Anura). Zoologia 26 (3): 413-418.

Newman R.A. 1988. Adaptive plasticity in development of Scaphiopus couchii tadpoles in desert ponds. Evolution $\mathbf{4 2}$ (4): $774-783$.

Peacor S.D. 2002. Positive effects of predators on prey growth rate through induced modifications of prey behavior. Ecol. Lett. 5 (1): 77-85. DOI: $10.1046 / \mathrm{j} .1461-0248.2002 .00287 . x$

Petranka J.W. \& Hayes L. 1998. Chemically mediated avoidance of a predatory odonate (Anax junius) by American toad (Bufo americanus) and wood frog (Rana sylvatica) tadpoles. Behav. Ecol. Soc. 42 (4): 263-271. DOI: $10.1007 / \mathrm{s} 002650050438$

Pfennig D.W., Mabry A. \& Orange D. 1991. Environmental causes of correlations between age and size at metamorphosis in Scaphiopus multiplicatus. Ecology 72: 2240-2248. DOI: http://dx.doi.org/10.2307/1941574

Relyea R.A. 2002. Competitor-induced plasticity in tadpoles: consequences, cues, and connections to predators induced plasticity. Ecol. Monogr. 72 (4): 523-540. DOI: 10.2307/ 3100055

Relyea R.A. 2003. How prey respond to combined predators: a review and an empirical test. Ecology 84 (7): 1827-1839. DOI: http://dx.doi.org/10.1890/0012-9658(2003)084[1827: HPRTCP $] 2.0 . \mathrm{CO} ; 2$

Relyea R.A. 2004. Fine-tuned phenotypes: tadpole plasticity under 16 combinations of predators and competitors. Ecology 85: 172-179. DOI: http://dx.doi.org/10.1890/03-0169 
Relyea R.A. 2007. Getting out alive: how predators affect the decision to metamorphose. Oecologia 152 (3): 389-400. DOI: $10.1007 / \mathrm{s} 00442-007-0675-5$

Relyea R.A. \& Werner E.E. 1999. Quantifying the relation between predator-induced behavioral responses and growth performance in larval anurans. Ecology 80 (6): 2117-2124. DOI: http://dx.doi.org/10.1890/0012-9658(1999)080[2117: QTRBPI] 2.0.CO;2

Reques R. \& Tejedo M. 1995. Negative correlation between length of larval period and metamorphic size in natural populations in natural populations of natterjack toads (Bufo calamita). J. Herpetol. 29: 311-314.

Richter-Boix A., Tejedo M. \& Rezende E. 2011. Evolution and plasticity of anuran larval development in response to desiccation. A comparative analysis. Ecol. Evol. 1 (1): 15-25. DOI: $10.1002 /$ ece3.2

Skelly D.K. 1995. Competition and the distribution of spring peeper larvae. Oecologia 103 (2): 203-207. DOI: 10.1007/ BF00329081

Tejedo M. \& Reques R. 1992. Effects of egg size and density on metamorphic traits in tadpoles of the natterjack toad (Bufo calamita). J. Herpetol. 26: 146-152.

Tejedo M. \& Reques R. 1994. Does larval growth history determine timing of metamorphosis in anurans? A field experiment. Herpetologica 50 (2): 113-118.

Teplitsky C. \& Laurila A. 2007. Flexible defense strategies: competition modifies investment in behavioral vs. morphological defenses. Ecology 88 (7): 1641-1646. PMID: 17645010
Tollrian R. \& Harvell D. (eds) 1999. The Ecology and Evolution of Inducible Defences. Princeton University Press, Princeton, New Jersey, 395 pp. ISBN: 9780691004945

Travis J. 1984. Anuran size at metamorphosis: Experimental test of a model based on intraspecific competition. Ecology 65: 1155-1160. DOI: http://dx.doi.org/10.2307/1938323

Van Buskirk J. \& Relyea R.A. 1998. Selection for phenotypic plasticity in Rana sylvatica tadpoles. Biol. J. Linn. Soc. 65 (3): 301-328. DOI: 10.1111/j.1095-8312.1998.tb01144.x

Warner S.C., Dunson W.A. \& Travis J. 1991. Interaction of pH, density, and priority effects on the survivorship and growth of two species of hylid tadpoles. Oecologia 88 (3): 331-339. DOI: $10.1007 /$ BF00317575

Wassersug R.J. 1975. The adaptive significance of the tadpole stage with comments on the maintenance of complex life cycles in anurans. Am. Zool. 15 (2): 405-417. DOI: $10.1093 / \mathrm{icb} / 15.2 .405$

Werner E.E. \& Peacor S.D. 2003. A review of trait-mediated indirect interactions in ecological communities. Ecology 84 (5): 1083-1100. DOI: http://dx.doi.org/10.1890/00129658(2003)084[1083:AROTII]2.0.CO;2

West-Eberhard M.J. 1989. Phenotypic plasticity and the origins of diversity. Annu. Rev. Ecol. Syst. 20: 249-278. DOI: 10.1146/annurev.es.20.110189.001341

Wilbur H.M. 1980. Complex life cycles. Annu. Rev. Ecol. Syst. 11: 67-93. DOI: 10.1146/annurev.es.11.110180.000435

Received October 10, 2013 Accepted August 20, 2014 